\title{
S2A Figs
}
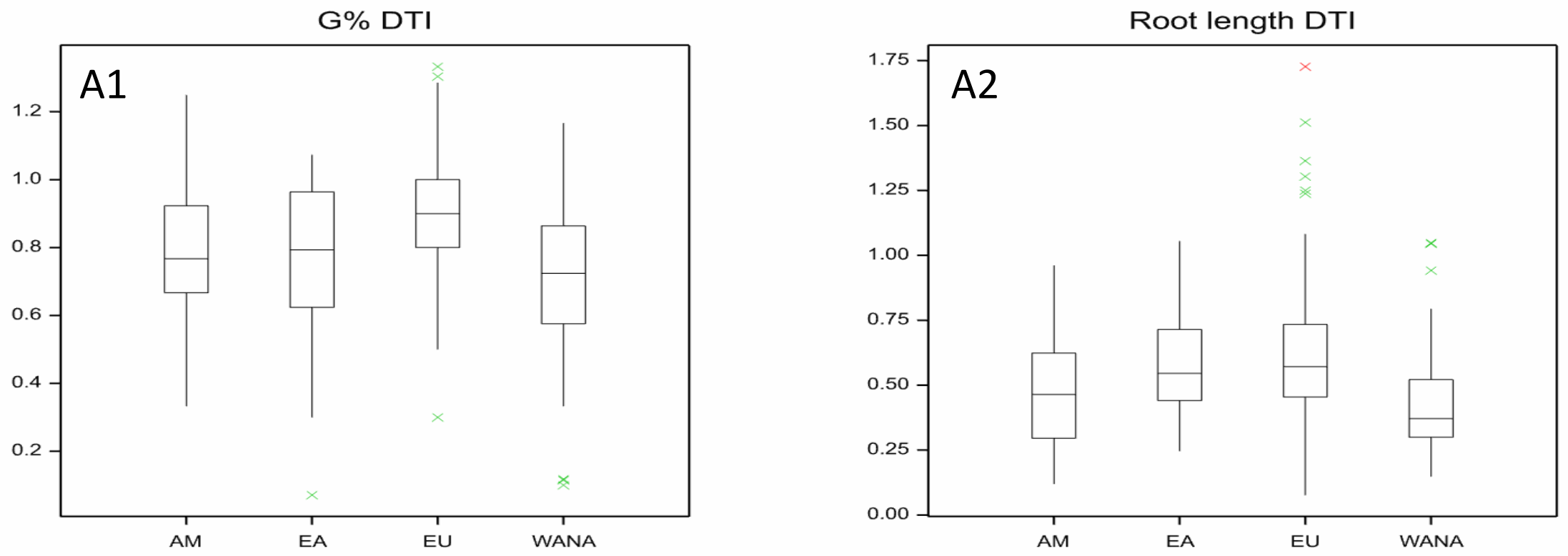

Shoot length DTI

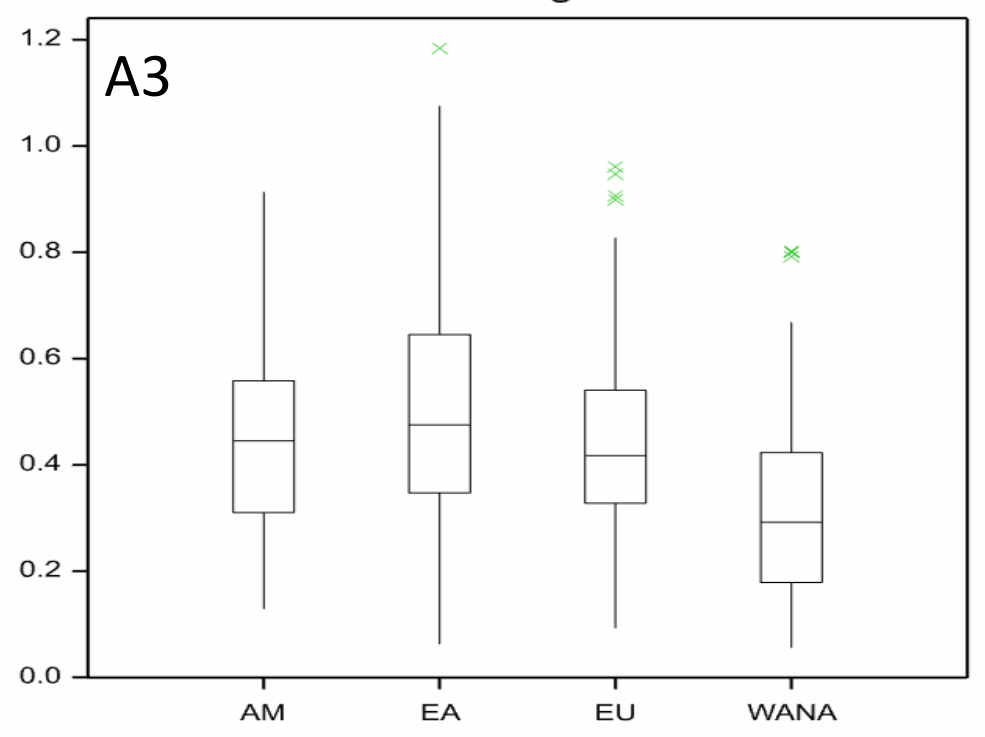

FW DTI

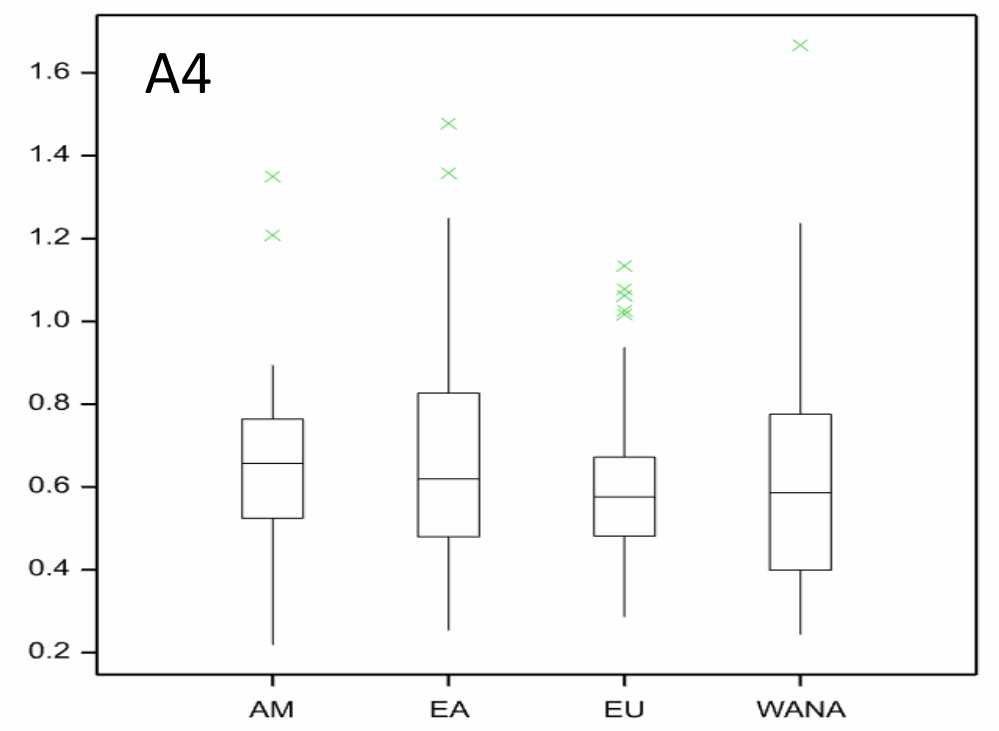




\section{S2B Figs}
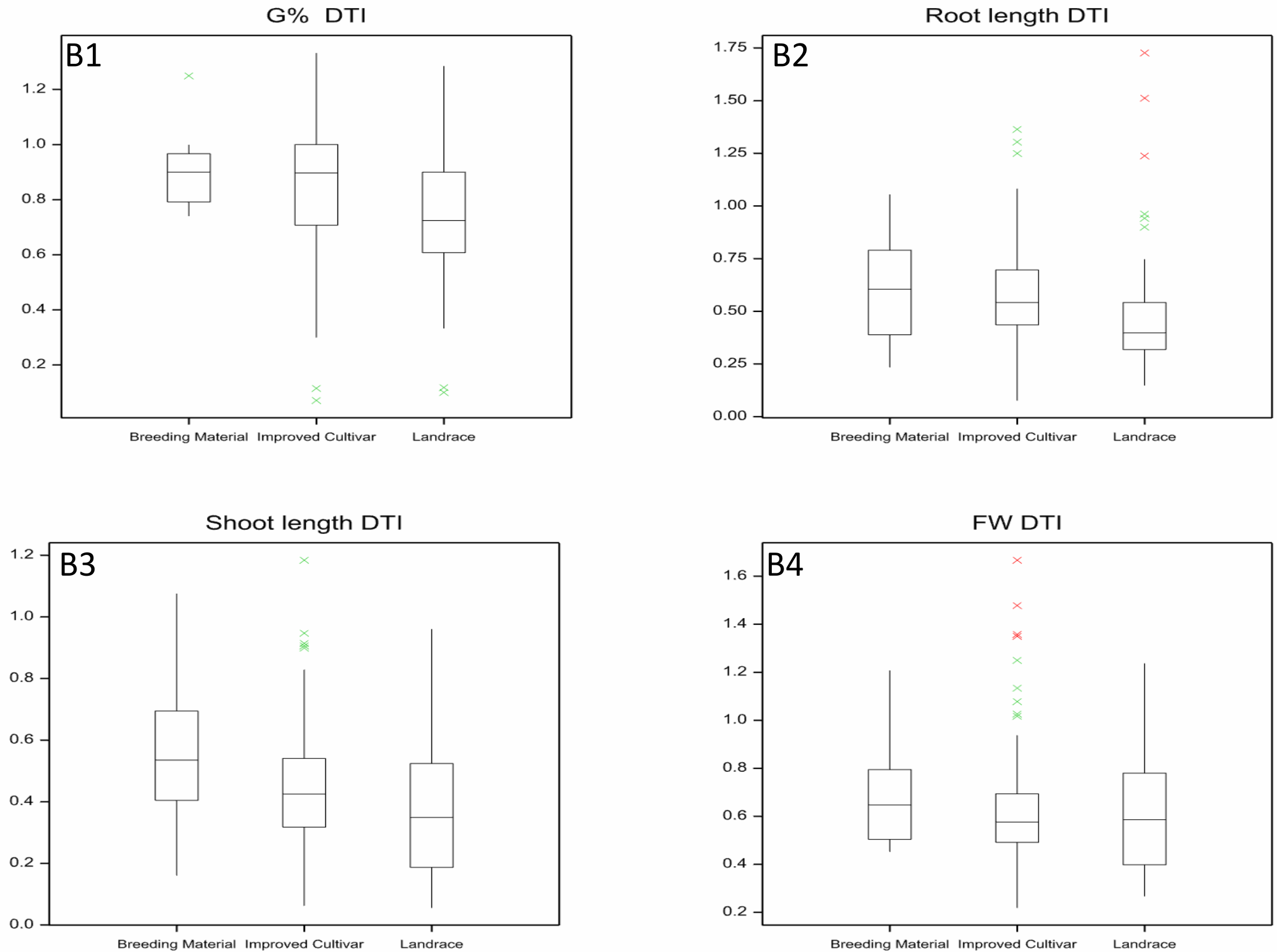


\section{S2C Figs}

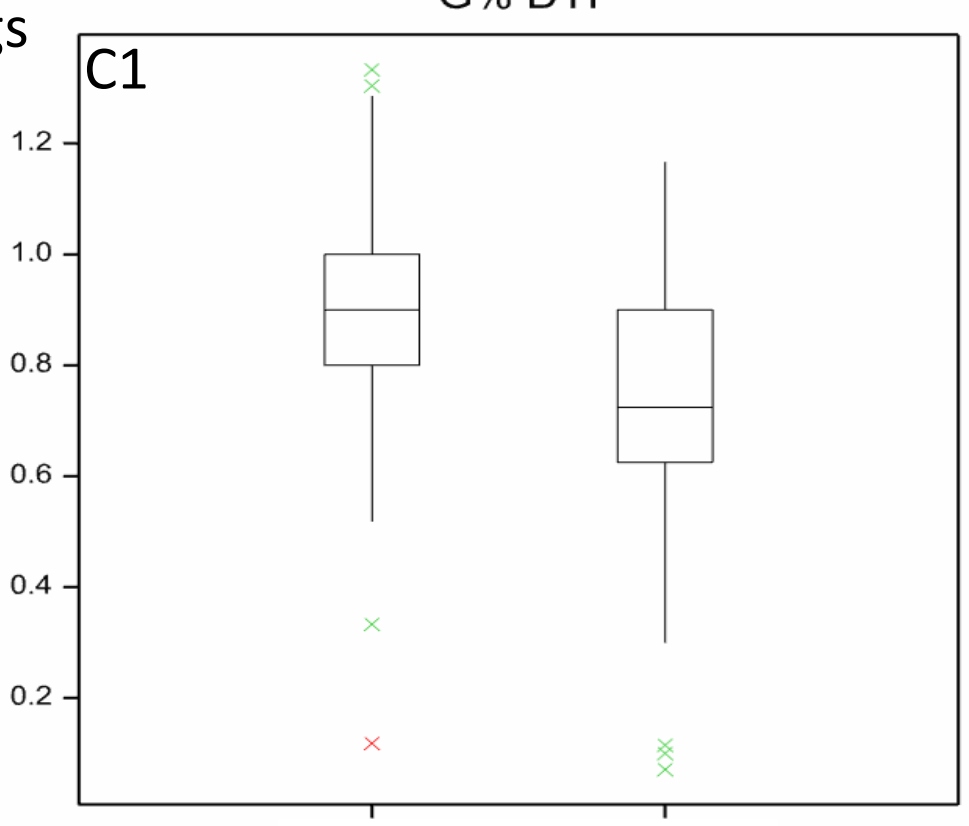

Two_rowed

Six_rowed

Shoot length DTI

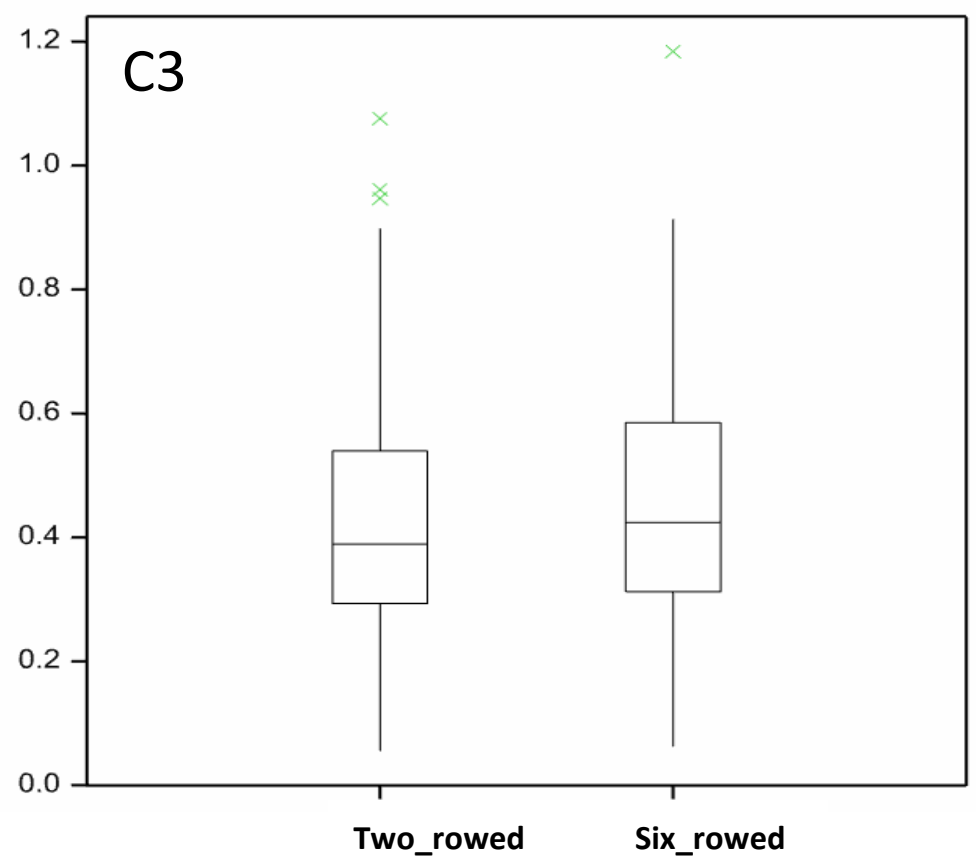

Root length DTI

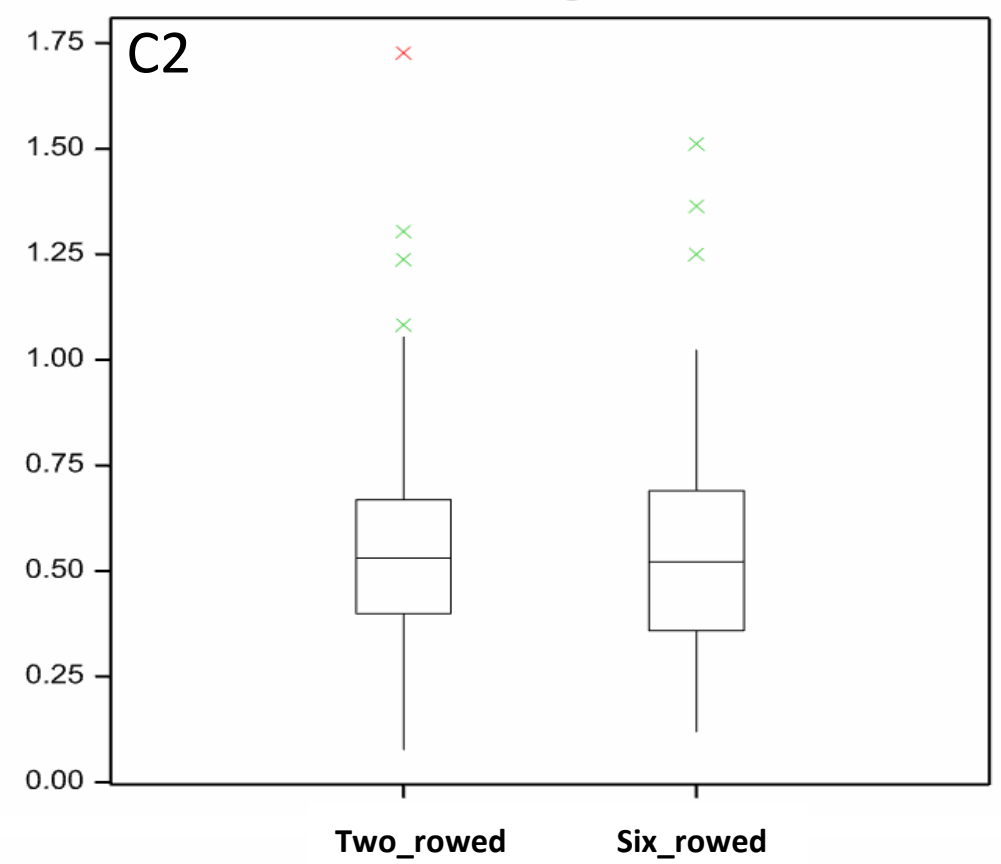

FW DTI

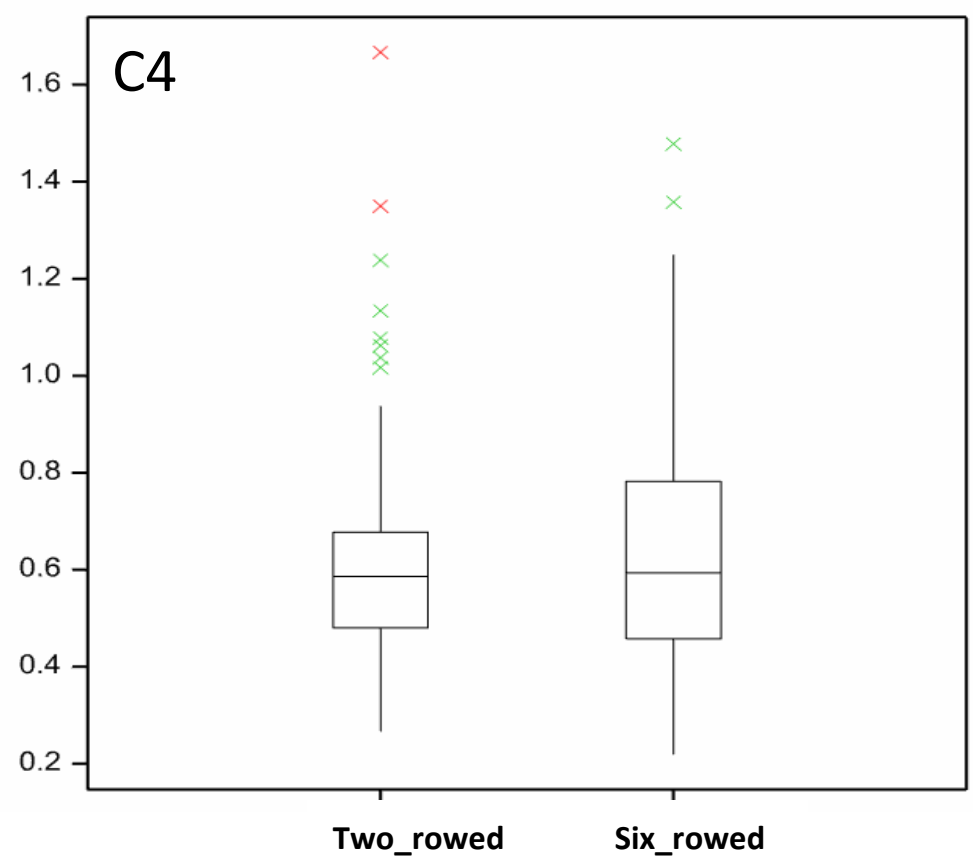

